\title{
PERCEPÇÃO AMBIENTAL: CONTRIBUIÇÕES E PRÁTICAS INDÍGENAS PARA O ENSINO DE CIÊNCIAS NO BAIXO RIO NEGRO
}

\author{
Francisco César Brito Vieira ${ }^{1}$
}

\author{
Josefina Barrera Kalhil ${ }^{2}$
}

Maria Auxiliadora Ruiz ${ }^{3}$

RESUMO: O presente trabalho é fruto de pesquisa e vivência nas comunidades indígenas, Terra Preta, Três Unidos e Nova Esperança, localizadas no baixo rio Negro, zona rural de Manaus. A experiência aqui relatada tem como objetivo mostrar que as sociedades indígenas são portadoras de conhecimentos que necessitam serem inseridos na educação formal pela relevância de sua contribuição e respeito ao meio ambiente. Os procedimentos metodológicos foram norteados pela pesquisa participante a fim de possibilitar maior interação entre o pesquisador e seu objeto de estudo. A reflexão da pesquisa foi orientada pelo método etnográfico que enfatiza a intenção de interpretar e compreender como se dá o processo de construção dos saberes tradicionais e respeito pelo meio ambiente, relacionando os seus significados com o homem e o seu meio. As comunidades indígenas, além de buscarem uma alternativa rentável através de práticas

\footnotetext{
1 Mestre em Ensino de Ciências na Amazônia, formado pela Escola Normal Superior - ENS, da Universidade do Estado do Amazonas/UEA.

2 Dra., em Física e Professora do Programa de Pós Graduação e Ensino de Ciências na Amazônia, pela Escola Normal Superior - ENS, da Universidade do Estado do Amazonas/UEA.

${ }^{3}$ Dra., em educação e Professora do Programa de Pós Graduação e Ensino de Ciências na Amazônia, pela Universidade Federal do Amazonas / UFAM.
} 
sustentáveis como o artesanato, passam valores as futuras geraçoes sobre sustentabilidade e manutençao do seu habitat. Os dados foram coletados através das técnicas de observação direta, e do uso de entrevista semi-estruturada a fim de contextualizar e compreender os significados das informações obtidas. A mudança, nos aspectos socioculturais e de conhecimentos, é um processo inevitável e irreversível que às vezes aparece de forma violenta. Acreditamos que o presente trabalho é de profunda relevância para professores e pesquisadores por suscitar uma questão que é sempre atual como questão ambiental. Diante disso percebe-se que a necessidade da construção de projetos mais eficazes de parcerias que possam dar respaldo aos interesses dessas comunidades indígenas para que ocorram significativas trocas, onde haja reconhecimento e valorização desses conhecimentos para que, a educação, saberes tradicionais, percepção ambiental e a sustentabilidade caminhem sempre juntos, possibilitando aos povos indígenas a preservação das suas culturas e do meio ambiente onde vivem.

Palavras chaves: Conhecimentos. Indígenas. Meio Ambiente e Sustentabilidade.

\section{INTRODUÇÃO}

O contexto histórico da comunidade Terra Preta iniciou com a chegada de dois indígenas da etnia Baré, Laurentino Aleixo e Lauro Bruno, oriundos do alto rio Negro, município de São Gabriel da Cachoeira, Rio Içana, a partir do ano de 1985. Como conseqüências disso a maioria das pessoas que chegaram ao local, criaram um vínculo familiar. A comunidade Terra Preta está situada à margem esquerda do Rio Negro, no município de Manaus, aproximadamente a quatro horas de barco. Atualmente a comunidade é constituída por trinta e oito (38) famílias num total de cento e oitenta (180) pessoas, entre adultos e crianças.

Já as comunidades Três Unidos e Nova Esperança estão localizadas na margem direita do rio Cuieiras, afluente do rio Negro. A comunidade Três Unidos é de etnia kambeba e são oriundos do alto rio Solimões, são quinze famílias que tem laço familiar num total de cinqüenta e cinco pessoas entre adultos e crianças. Vivem da pesca, caça e produção de artesanato, a comunidade dispõe de uma escola multiseriada que funciona do primeiro ao quinto ano, um posto de saúde e poço artesiano, e é assistida pela FUNAI (Fundação Nacional do Índio) e COIAB (Comissão Indígena da Amazônia Brasileira). 
$\mathrm{Na}$ comunidade Nova Esperança são vinte e oito famílias de etnia baré, oriundas do município de Santa Isabel médio rio Negro, também vivem da caça, pesca, roça e artesanato. A maioria tem vínculo familiar e a comunidade dispõe de uma escola onde é ministrado o ensino fundamental do primeiro ao quinto ano também em uma sala multiseriada. A comunidade dispõe de um poço artesiano e desenvolve um projeto experimental de piscicultura em gaiola. Como podemos observar essas comunidades tem muitas coisas em comum, entre elas podemos elencar: saberes tradicionais, alimentação, educação, habitam no mesmo rio, produzem e vendem artesanato como complemento da renda familiar.

O nosso objeto de pesquisa visou uma reflexão da percepção ambiental indígena e a produçao de artesanato nessas comunidades e que contribuições elas trazem para as práticas ambientais.

As Comunidades Terra Preta, Três Unidos e Nova Esperança, são constituída pelas relações entre famílias de origem Baré, Baniwa, Tukano, Macuxi, Mura, Kambeba, Mundurucu, Tariano e Werekena. Percebe-se que há uma valorização das questões ambientais em seus processos educativos e que essa se dá de maneira informal na sua cotidianidade nas relações com diversas culturas. Os povos indígenas são detentores de conhecimentos tradicionais milenares que necessitam serem cada vez mais valorizados, reconhecidos e inseridos nos processos educativos da educação escolar da sociedade envolvente e na educação ambiental.

\section{A PERCEPÇÃO AMBIENTAL}

A Educação Ambiental está inserida nos Parâmetros Curriculares Nacionais (PCN's) das escolas, isto surgiu diante da preocupação com a formação de atitudes relacionadas a esta temática. A escola proporciona mudanças de atitudes de seus alunos com relação ao ambiente, pois, tem procurado através de diferentes disciplinas, proporcionarem informações relativas ao meio ambiente.

Assim, o estudo do meio ambiente é de fundamental importância para que possamos compreender melhor as inter-relações entre o homem e o ambiente, suas expectativas, satisfações e insatisfações, julgamentos e condutas (FAGGIONATO, 2002). 
Saber como os alunos de ensino fundamental conceituam o ambiente em que vivem suas fontes de satisfação e insatisfação é de fundamental importância, pois possibilita a realização de um trabalho com bases locais, partindo da realidade do público alvo.

A educação ambiental ressalta peculiaridades sociais nas quais estão implícitas relações humanas, e está muito presente e ligada em todas as culturas além de proporcionar, interação, aprendizado, respeito e diálogo. "O saber indígena vem de práticas comunitárias do saber ser, saber estar, saber dar uso, de um mundo que se reconhece na convivência e nas práticas". LEFF e MUÑOZ (2003).

A educação ambiental não pode ser ignorada, uma vez que ela se faz presente e acontece nas relações cotidianas, nos espaços das comunidades, na escolas, e tem o papel fundamental como agente de formação, informação e transformação na valorização dos saberes, minimizando assim as diferenças existentes entre as raças, buscando um equilíbrio entre ser humano e natureza a partir da compreensão e sensibilização dessa interrelação.

Os educadores não podem ficar alheios as questões ambientais que as nossas cidades/escolas já estão enfrentando. A educação ambiental exerce um papel importante na escolarizacão, e preparação do estudante para a cidadania. As escolas existentes nas comunidades são frutos de uma parceria entre a própria comunidade e Secretaria Municipal de Educação (SEMED). O ensino vai da alfabetização a quarta série, onde todas as crianças compartilham de uma sala multiseriada. Porém mantém a língua geral (nheengatu) como uma estratégia de sobrevivência diante da diversidade e afirmação de identidade, no entanto falam bem o português.

Os moradores não praticam mais muito dos seus antigos rituais, pois a maioria foi influenciada em seus costumes, valores e crenças pela cultura da sociedade envolvente, tornando suas tradições e costumes diferentes.

O ensino se dá de forma tradicional nos padrões da educação da sociedade envolvente, com a inserção de elementos dos saberes tradicionais. A educação também acontece de maneira informal fora do espaço da escola, onde a língua nheengatu é ensinada através de músicas e histórias, e muitas das aulas de ciências são trabalhadas no cotidiano e convivência com os pais e os professores, sobre plantas medicinais, artesanato e cerâmica. 
Não há uma forma única nem um único modelo de educação; a escola não é o único lugar onde ela acontece e talvez nem seja o melhor; o ensino escolar não é sua única prática e o professor profissional não é o seu único praticante. Em mundos diversos a educação existe diferente: em pequenas sociedades tribais de povos caçadores [...] (BRANDÃO, 2004. p 9).

\section{EDUCAÇÃO E DIVERSIDADE}

Historicamente, a introdução da escola em meio indígena serviu de instrumento de imposição de valores alheios e de negação de identidades diferenciadas, por meio de diferentes processos, como a catequização, a civilização e a integração forçada dos índios à comunhão nacional. Em anos recentes, a escola ganhou um novo sentido para os povos indígenas, tornando-se um meio de acesso a conhecimentos universais de valorização, sistematização de saberes e conhecimentos tradicionais.

De algo imposto, a educação e a criação de escolas em terras indígenas passou a ser uma demanda dos próprios povos indígenas, interessados em adquirir conhecimentos sobre o mundo de fora das aldeias e em construir novas formas de relacionamento com a sociedade envolvente e com o mundo. A questão da escola ganha importância na medida em que se percebe que os índígenas precisam adquirir conhecimentos qualificados sobre o mundo dos brancos, para que possam estabelecer relações menos submissas e mais igualitárias tanto com setores do indigenismo oficial, quanto com outros segmentos da sociedade brasileira.

Hoje a demanda pela escola deve estar presente em quase todas as comunidades indígenas que mantêm relacionamentos com segmentos da sociedade brasileira. E essa demanda não é por qualquer tipo de escola, mas por uma escola gerida por representantes das comunidades indígenas, que permita 0 acesso a saberes universais, servindo de ponto de referência para processos de valorização, de resgate cultural e principalmente reconhecimento dos etnoconhecimentos.

A diversidade não pode ser ignorada, uma vez que ela se faz presente e acontece nas relações cotidianas e espaços da comunidade e da esocla, e é essa que tem o papel fundamental como agente de formação e transformação aproveitando os saberes já existentes e minimiza as diferenças e nivela as relações a partir do diálogo. 
Os (as) educadores(as) não poderão ignorar, as difícies questões do multiculturalismo, da raça, da identidade, do poder, do conhecimento, da ética e do trabalho que, na verdade, as escolas já estão tendo de enfrentar. Essas questões exercem um papel importante na definição do significado e do propósito da escolarização, no que significa ensinar e na forma como os (as) estudantes devem ser ensinados (as) para viver em mundo que será amplamente globalizado (...) (GIROUX,2002, p.5)

Percebe-se que os indígenas não só querem conhecer cada vez mais a nossa cultura, como também inserir no seu dia-a-dia a nossa educação formal. Isso foi observado nas falas do presidente da comunidade:

A cultura de vocês traz muitas coisas boas como à escola e outros benefícios e nos orienta a lutar pelos nossos direitos, mais a cultura de vocês só pensa em ganhar e ter vantagem, mesmo que seja para destruir o local onde vocês vivem, Nós temos de pensar nas gerações que ainda virão. (ANILDO Baré, líder comunitário - Terra Preta, 2008)

Pode-se perceber através das palavras desse líder comunitário a preocupação com as questões ambientais e a importância da escola como uma estratégia de mediar o diálogo entre as culturas, mas também se percebe uma preocupação com alguns elementos da nossa cultura, que podem ser prejudiciais e nocivas para a natureza.

A comunidade Terra Preta possui um diálogo intercultural com a cultura ocidental, adquirindo nossos hábitos e costumes, mas os conhecimentos só são modificados quando analisados e considerados benéficos para todos. A percepção das diferenças culturais e a incorporação de novas atitudes nessa sociedade causam mudanças, onde estas ocorrem aos poucos e, sucessivamente são passadas aos descendentes, que vão assumindo uma nova postura de convivência. Os costumes tradicionais estão sendo deixados de lado como conseqüência do processo de globalização, porém os valores tradicionais continuam sendo passados de pai para filho.

\section{ELEMENTOS DA FLORESTA E ARTESANATO}


A produção de artesanato é um dos pontos fortes dessas comunidades, pois, é um momento de ensinamento e aprendizado onde os pais passam aos filhos seus conhecimentos e a forma de trabalhar os elementos da floresta de forma a gerar respeito e relação equilibrada com a mesma.

Durante a produção de artesanato são confeccionados colares, pulseiras, utensílios de caça, anéis entre outros. E todo esse material é produzido a partir de sementes de várias espécies que são coletadas na natureza, fibras de árvores, troncos de árvores caídas, ossos e penas de animais que são mortos em caçadas (só caçam para comer). A produção do artesanato é um momento de criatividade na confecção das peças, na mistura das tintas para obter a coloração ideal que combine com as sementes. Também é nesse momento que são passadas lições sobre respeito e cuidados com a natureza, pois isto gera uma relação dicotômica e de interdependência

\section{ARTESANATO E FONTE DE RENDA}

O artesanato constitui-se numa fonte de renda para essas populações, pois ao mesmo tempo em que se trabalham os conhecimentos e saberes tradicionais, a relação de equilíbrio, aprendizado e criatividade, esses produtos são vendidos para os turistas que visitam essas comunidades, tanto brasileiros como estrangeiros.

O que nos arrecadamos é para ajudar nas nossas despesas de casa, comprar um açúcar, uma rede, um calçado, óleo ou ajudar no diesel para o gerador da comunidade. Essa renda nos ajuda muito, e, é uma forma de mostrar que nos temos capacidade de fazer arte, de ensinar e aprender com facilidade sobre outras culturas. (VALDEMIR KAMBEBA, líder comunidade Três Unidos, 2008).

Cada família tem uma mesa ou barraca onde são expostos os produtos e há relatos de famílias que arrecadam até quatrocentos reais por mês. Os preços das peças variam entre cinco e quarenta reais e o faturamento ajuda nas despesas de cada família.

Outro momento de rico aprendizado é quando os professores trabalham cálculos de matemática sobre os produtos que são negociados. Por quanto foi vendido, o que dá para comprar com o dinheiro? E quanto resta de troco? 


\section{A IMPORTÂNCIA DOS PÁSSAROS E AVES PARA A FLORESTA}

Em certa ocasião estava na comunidade realizando observações na casa de farinha onde se encontravam algumas famílias torrando a massa, descascando e ralando mandioca, observei que dentro de um paneiro tinham dois cachos de pupunha, um era mais vistoso que o outro, falei que gostaria de comprar o cacho de pupunha ao Feliciano de etnia Werekena que era o proprietário da referida fruta, fiquei surpreso quando ele me falou que eu poderia ficar com as frutas e não custaria nada. Mas quando peguei o cacho, percebi que ele estava bastante comido por ação das aves, e fiz o seguinte comentário, se você não chega mais rápido as aves acabariam com o cacho de pupunha, porém fiquei surpreso com a resposta dele: "Não, as aves também precisam se alimentar e quando elas comem, elas vão semeando os caroços pela floresta e a partir daí vai nascendo novos pés". Houve um momento de silêncio e perguntei com quem ele havia aprendido aquilo e sua resposta foi, com meu pai e ele aprendeu com o pai dele.

\section{PESCA PARA AS FUTURAS GERAÇÕES}

Em outra ocasião estava observando o seu Olavo (etnia baré), remendando a sua malhadeira com certa habilidade, me aproximei dele e perguntei o que havia ocasionado àqueles buracos, sua resposta foi: “isto foi à ação das piranhas e dos jacarés". E lá pelo meio da conversa perguntei por que ele não pescava bastante para vender o excedente, sua resposta foi: nós temos de pensar nos nossos filhos e netos, se todo mundo começar a fazer isso, vai ficar cada vez mais escasso, nós só pescamos e caçamos para comer e dividir com nossos parentes (Termo usado pelos indígenas para designar as pessoas de outras etnias), os brancos não são assim, vocês não gostam de dividir, vocês só pensam em vocês.

\section{EQUILÍBRIO E SUSTENTABILIDADE}

Durante o período de pesquisa na comunidade, pudemos observar muitas situações de cuidados com o meio ambiente. A comunidade está sempre limpa apesar do 
uso de enlatados, plásticos e descartáveis. A confecção do artesanato é feita de material aproveitado como sementes, madeira, corantes e plumagem de animais mortos em caçada. A destinação do lixo tem um lugar apropriado onde todos os moradores levam lixo e os resíduos são queimados. Portanto há uma relação muito grande de afeto e respeito com os animais silvestres, onde os filhotes das caças abatidas são criados como um membro da família.

Existe um respeito pela natureza, onde são ensinados às futuras gerações que é possível essa dicotomia, homem e natureza convivendo de forma harmoniosa.

\section{CONSIDERAÇÕES FINAIS}

A preservação dessas comunidades depende da forma de trabalhar os antigos e os novos conhecimentos em torno de projetos, esses novos costumes agregados à sua cultura, não implicam na extinção dos saberes existentes, apenas sofrem modificações criando uma nova tendência de cultura com a incorporação de novos elementos numa perspectiva de transformação social.

A mudança, nos aspectos socioculturais e de conhecimentos, é um processo inevitável e irreversível que às vezes aparece de forma violenta. Diante disso percebe-se a necessidade da construção de projetos mais eficazes de parcerias que possam dar respaldo aos interesses dessas comunidades indígenas para que ocorram significativas trocas, onde haja reconhecimento e valorização desses conhecimentos para que, educação ambiental, saberes tradicionais e sustentabilidade caminhem sempre juntos, possibilitando aos povos indígenas preservação das suas culturas e do meio ambiente onde vivem.

\section{REFERÊNCIAS}

BARBIERI, José Carlos. Desenvolvimento e meio ambiente: as estratégias de mudanças da agenda 21. 7. ed. Rev. e atual. Perópolis, RJ: Vozes, 2005.

BRANDÃO, Carlos Rodrigues. O que é educacão. São Paulo, Brasiliense, 2004. 
CANDAU, Vera Maria. Sociedade Educacão e Cultura - Questões e propostas. Petrópolis, RJ: Vozes, 2002.

CHIZZOTTI, Antônio. Pesquisa qualitativa em ciências humanas e sociais. Petrópolis,RJ ; Vozes, 2006.

FREITAS, Marcílio de. (Org). Amazônia: a natureza dos problemas e os problemas da natureza. Manaus. EDUA, 2005.

GIROUX, Henry A. Os professores como intelectuais: Rumo a pedagogia crítica da aprendizagem. Porto Alegre: Artes Médicas, 1997.

MARCONI, Marina de Andrade; PRESOTTO, Zélia Maria Neves. Antropologia - uma introdução. 6. ed. São Paulo: Atlas, 2005.

MUNOZ, Maritza Gómez. LEFF, Enrique (org). A Complexidade Ambiental. São Paulo: Cortez, 2003.

REIGOTA, Marcos. O que é Educação Ambiental. São Paulo: Brasiliense, 2006.

SANTOS, Aparecido Gomes dos. BENTO, Antônio Henrique. Observando a Natureza. Manaus: EDUA, 2007.

SILVA, Aracy Lopes da. FERREIRA, Marina Kawall Leal. (Org). Antropologia, História e Educação: a questão indígena e a escola. 2. ed. - São Paulo: Global, 2001.

SCOTO, Gabriela. CARVALHO, Isabel Cristina de Moura, Guimaraes. Desenvolvimento sustentável. 3. ed. Petrópolis, RJ: Vozes, 2008.

VIANA, Virgílio. As florestas e o desenvolvimento sustentável na Amazônia. 2. ed. Manaus: Valer, 2007.

WEIGEL, Valéria Augusta Cerqueira de Medeiros. Escolas de branco em malokas de índio. Manaus: EDUA, 2000. 